\title{
Novel unroofing approach for incipient suprapapillary stone perforation causing papillary invagination ("the crescent sign")
}

This is the case of an 89-year-old man undergoing emergency endoscopic retrograde cholangiography (ERC) for acute cholangitis. However, no en face view of the papilla was obtained after duodenoscope advancement but instead an edematous bulky mass surrounded by a semilunar slit was visible. Fig. $\mathbf{1}$ a, b depicts the level of the papilla in the short and long axes, providing crescent-like clues to the diagnosis ("the crescent sign"). "High grade" edema with "papillary invagination" was confirmed by papillotome traction after probing the slit (\$ Fig. 1 c). Further palpation revealed an incipient suprapapillary stone perfora-

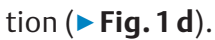

Conventional biliary access using various cannulae and techniques was unsuccessful. Therefore, we proceeded with an "unroofing" approach, cutting along the axis from the papilla to the perforation site ( $\mathbf{F i g . 2} \mathbf{a}, \mathbf{b}$ ), exposing the large impacted stone (\$Fig.2c). Selective biliary cannulation was achieved thereafter, and the stone subsequently passed ( Fig. 2 d). $\triangleright$ Fig. 2 e shows the flattened papillary mound at the 3 o'clock position ( $\triangleright$ Video 1). Next, an extensional guidewire-directed papillotomy along the bile duct axis was performed, and a stent was placed because of the remnant stone burden.

This unique report incorporates several novelties in both diagnostic and therapeutic approaches to bile duct stone impaction in the setting of a periampullary diverticulum (PAD) [1]. It is the first report of an occlusive infolding of the papillary region into a PADdue to stonerelated high-grade edema and axial distortion. Extending the spectrum of a "hidden papilla" in PAD, "the crescent sign" reflects what we may designate "papillary invagination," albeit not in its strictest sense [2]. Endoscopic manage-

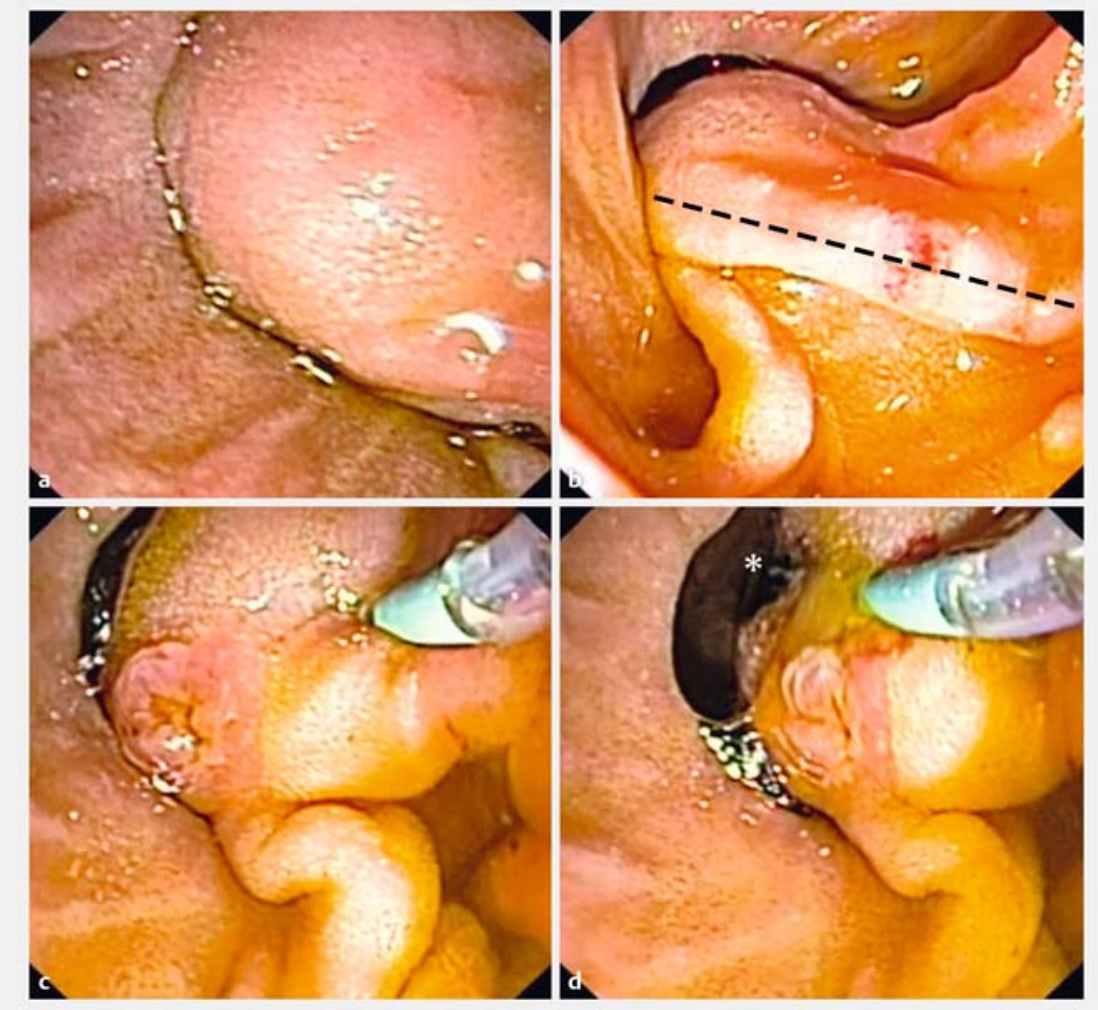

-Fig. 1 Diagnostic part- "The crescent sign" suggesting papillary invagination in the periampullary diverticulum related to incipient suprapapillary stone perforation. Duodenoscopic view at the level of the papilla in the short (a) and long (b) axes, revealing an edematous bulky mass surrounded by a crescent-shaped slit and a distorted longitudinal fold (dotted line in b). $\mathbf{c}$ Exposure of the papillary opening after papillotome traction. $\mathbf{d}$ Incomplete dorsocranial suprapapillary stone perforation (asterisk).

ment of incomplete stone perforation requires individualization, with options including standard papillotomy, needleknife papillotomy, or the presented "unroofing" approach [3].

Endoscopy_UCTN_Code_TTT_1AR_2AH

Competing interests
The Authors

Vincent Zimmer ${ }^{1,2}$, Frank Lammert ${ }^{2}$

1 Department of Medicine, Marienhausklinik St Josef Kohlhof, Neunkirchen, Germany

2 Department of Medicine II, Saarland University Medical Center, Homburg, Germany 

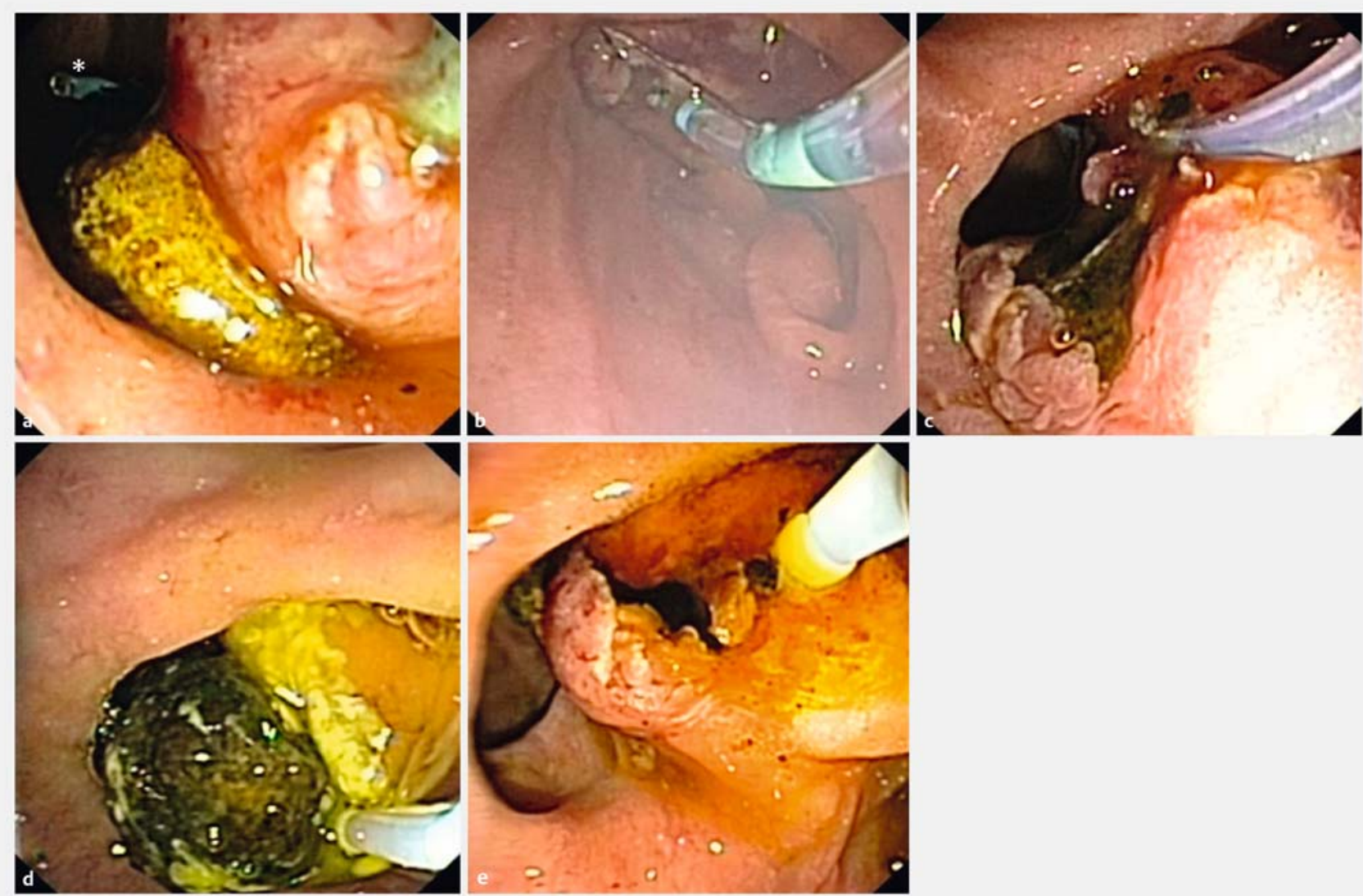

- Fig. 2 Therapeutic part - Novel "unroofing" approach for initial biliary access. a Deliberate cannulation from the papilla to the perforation site (asterisk, tip of the papillotome). b "Unroofing" by cutting along the axis from the papilla to the perforation site, similarly to conventional papillotomy. $\mathbf{c}$ Papillotome palpation exposed the entire stone. $\mathbf{d}$ Stone passage after biliary cannulation with a straight cannula. e Flattened papillary region after the intervention.

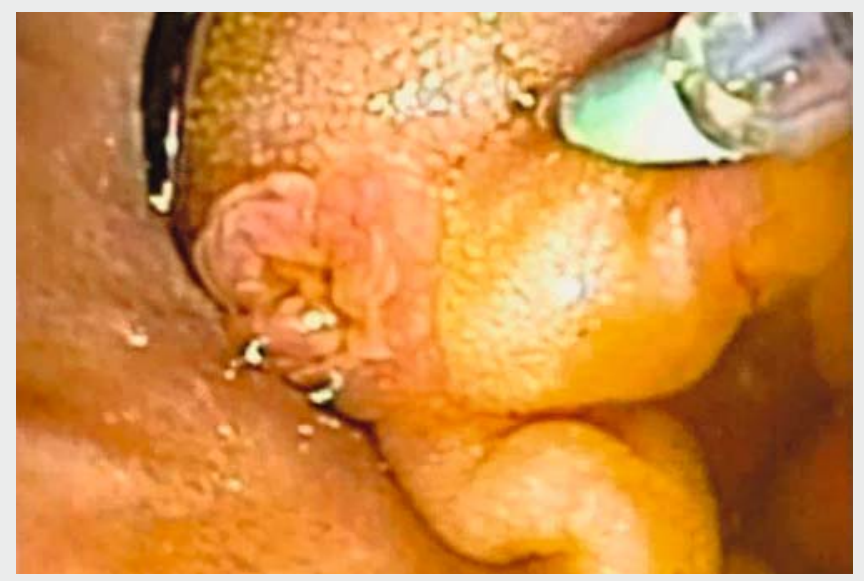

Video 1 The video showcases a novel diagnostic finding, for which the introduction of the term "papillary invagination" is suggested and which might be indicated by "the crescent sign." Furthermore, an innovative therapeutic approach to incomplete suprapapillary stone perforation in a setting of periampullary diverticulum is presented (i. e. an "unroofing" procedure cutting along the axis from the papilla orifice to the perforation site).

\section{Corresponding author}

\section{Vincent Zimmer, MD}

Department of Medicine, Marienhausklinik

St. Josef Kohlhof, Klinikweg 1-5, 66539

Neunkirchen, Germany

Fax: +49-6821-3632624

vincent.zimmer@gmx.de 


\section{References}

[1] Chen L, Xia L, Lu Y et al. Influence of periampullary diverticulum on the occurrence of pancreaticobiliary diseases and outcomes of endoscopic retrograde cholangiopancreatography. Eur J Gastroenterol Hepatol 2017; 29: 105-111

[2] Garcia-Cano J. ERCP cannulation of a hidden papilla within a duodenal diverticulum. Endoscopy 2008; 40 (Suppl. 02): E53
[3] Altonbary AY, Bahgat MH. Endoscopic retrograde cholangiopancreatography in periampullary diverticulum: the challenge of cannulation. World J Gastrointest Endosc 2016: $8: 282-287$

\section{Bibliography}

DOI https://doi.org/10.1055/s-0043-109235

Endoscopy 2017; 49: E181-E183

(C) Georg Thieme Verlag KG

Stuttgart · New York

ISSN 0013-726X

\section{ENDOSCOPY E-VIDEOS}

https://eref.thieme.de/e-videos

口7: Endoscopy E-Videos is a free access online section, reporting

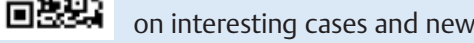
techniques in gastroenterological endoscopy. All papers include a high quality video and all contributions are freely accessible online.

This section has its own submission website at

https://mc.manuscriptcentral.com/e-videos 